\title{
Evidenciação de custos ambientais em empresas do segmento de adubos e fertilizantes
}

\author{
Environmental costs disclosure in manure and fertilizer business segment
}

\section{Jeniffer Monteiro Rodrigues}

Especialista em Ciências Contábeis na Universidade Federal de Rio Grande

Endereço: Avenida Itália, 1662, casa 105, Bairro Vila Maria

CEP: 96203-000 - Rio Grande/RS - Brasil

E-mail: jmonteirorodrigues@yahoo.com.br

Telefone: (53) 9104-5727

\section{Débora Gomes Machado}

Mestre em Ciências Contábeis na Universidade do Vale do Rio dos Sinos

Doutoranda em Ciências Contábeis e Administração na Universidade Regional de Blumenau

Professora do Instituto de Ciências Econômicas, Administrativas e Contábeis da Universidade Federal de Rio Grande Endereço: Rua Antônio da Veiga, 140 - Sala D 202, Bairro Victor Konder - Caixa Postal 1507

CEP: 89012-900 - Blumenau/SC - Brasil

E-mail: debora_furg@yahoo.com.br

Telefone: (47) 3321-0565

\section{Ana Paula Capuano da Cruz}

Mestre em Contabilidade na Universidade Federal do Paraná

Doutoranda em Controladoria e Contabilidade na Universidade de São Paulo

Endereço: Alameda Uruguay, 55, Bairro Vila Maria José

CEP: 96203-040 - Rio Grande/RS - Brasil

E-mail: anapaulacapuanocruz@hotmail.com

Telefone: (53) 3230-2417

Artigo recebido em 17/04/2010. Revisado por pares em 15/07/2010. Reformulado em 17/09/2010. Recomendado para publicação em 02/06/2011 por Sandra Rolim Ensslin (Editora Científica). Publicado em 18/11/2011. Artigo apresentado XVII Congresso Brasileiro de Custos, 2010, Belo Horizonte, 2010. 


\title{
Resumo
}

Este estudo objetivou verificar como as empresas abertas do segmento de adubos e fertilizantes têm classificado e evidenciado seus custos de natureza ambiental. Metodologicamente, trata-se de um estudo descritivo, desenvolvido por meio da técnica de análise de conteúdo com apoio do software Atlas.ti ${ }^{\circledR}$. Analisaram-se os relatórios de administração e as demonstrações contábeis relativas ao exercício de 2008 das 4 empresas do segmento supracitado. Os resultados apontam que, em geral, as empresas manifestam preocupação com questões sociais e ambientais, porém restringem-se a evidenciações puramente qualitativas de informações dessa natureza. Constatou-se que, mesmo com a mudança de postura em relação à conscientização ambiental, ainda há muito a ser feito, principalmente com relação à combinação de informações ambientais com os Relatórios de Administração e Demonstrações Financeiras obrigatórias, de modo a possibilitar maior transparência aos usuários destas informações.

Palavras-chave: Gestão ambiental. Custos ambientais. Evidenciação de informações ambientais.

\begin{abstract}
This study aimed to verify how the Brazilian companies of the segment of manure and fertilizers have been classifying and evidencing its costs of environmental nature. Methodologically, this is a descriptive study, developed through the technique of content analysis supported by the Atlas.ti ${ }^{\circledR}$ software. The management reports and financial statements for the year of 2008 from four companies in the segment were analyzed. The results indicate that, in general, companies are concerned with social and environmental issues, but are restricted to report purely qualitative information of this nature. It was verified that even with the posture change from the part of the companies in relation to the environmental understanding, it can be affirmed that there is still a lot to improve, mainly regarding the combination of the environmental information with the reports and traditional financial demonstrations, making possible a greater transparency to the users of these information.
\end{abstract}

Keywords: Environmental management. Environmental costs. Environmental Information. Disclosure.

\section{Introdução}

As mudanças sócio-culturais das últimas décadas e a crescente consciência ambiental têm contribuído à assunção de uma nova postura por parte das empresas. Nesse sentido, a utilização dos recursos disponíveis de modo a não comprometer sua disponibilidade futura, manifesta-se como uma das formas de atender às exigências da sociedade e do Governo quanto à preservação do meio ambiente e ao desenvolvimento sustentável. Os impactos ambientais, associados aos prejuízos causados à humanidade, muitas vezes decorrentes do uso de "tecnologias sujas" pelas indústrias, e pelo uso desmedido dos recursos naturais, contribuíram à discussão de questões ambientais pela sociedade em geral. Nesse contexto, consideram-se "tecnologias sujas" aqueles recursos de natureza tecnológica que não estão alinhados às boas práticas de conduta para manutenção sustentável do meio ambiente.

Estas mudanças parecem afetar significativamente o meio empresarial, pois a nova concepção de política ambiental faz com que os consumidores tenham 
preferência por produtos que degradem menos o meio ambiente, fazendo com que as empresas adotem práticas ambientais sustentáveis. Em decorrência dessas pressões da sociedade em geral, os investidores e demais usuários da contabilidade passam a exigir maior transparência das empresas, visto que a evidenciação exigida nas demonstrações obrigatórias refere-se, sobretudo, ao desempenho financeiro e econômico e não de cunho ambiental e social.

Assim, em resposta às expectativas e pressões de cunho social e legal, inúmeras empresas têm optado pela divulgação, ainda que de forma voluntária, de informações de natureza ambiental (CLARKSON et al, 2008). Todavia, paralelamente a essa divulgação, visualiza-se a constante necessidade de controle e mensuração dos custos relacionados aos impactos ambientais, face à sua relevância na tomada de decisão.

Considerando as argumentações reunidas, associadas à dificuldade e necessidade de obtenção de informações que dizem respeito aos custos de natureza ambiental e ainda, tendo em vista a dificuldade de sua mensuração, o presente estudo busca responder a seguinte questão: Como as empresas instaladas no Brasil do segmento de adubos e fertilizantes têm classificado e evidenciado os custos de natureza ambiental? O objetivo é verificar de que forma as empresas brasileiras do segmento de adubos e fertilizantes têm classificado e evidenciado seus custos de natureza ambiental. Para operacionalização da investigação, procedeu-se: [1] a identificação das empresas instaladas no Brasil que submetem suas ações à negociação pública na Bolsa de Valores, Mercadorias \& Futuros (BM\&FBOVESPA) e são exploradoras do segmento de adubos e fertilizantes; [2] coleta das Demonstrações Contábeis, dos Relatórios de Administração e dos Balanços Sociais de tais empresas relativos ao exercício de 2008; e [3] análise de conteúdo das informações coletadas para verificação do processo de classificação e evidenciação dos custos de natureza ambiental.

As crescentes mudanças no mercado que, entre outras implicações, contribuem para o crescimento da demanda por informações contábeis de natureza ambiental, sinalizam a importância desse estudo. Conforme Guesser e Beuren (1998), o incremento de metodologias que permitam a identificação e mensuração dos custos de natureza ambiental representa um processo de recorrência à academia para minimizar problemas de ordem profissional. Adicionalmente, Rossato, Trindade e Brondani (2009, p. 72) atentam à necessidade de se "conhecer o processo de identificação, reconhecimento e evidenciação pelas entidades que, de alguma forma ou de outra, interagem com o meio ambiente e que necessitam dessas informações para melhor gerir e avaliar o seu desempenho na área ambiental." A carência de pesquisas relativas à evidenciação de informações contábeis ambientais, sobretudo na área de custos, representa outro fator relevante à condução do estudo. As publicações identificadas mostram-se concentradas sob o enfoque 
quantitativo (LIMA et al, 2008; MACEDO et al, 2008; VAZ et al, 2008; ROVER et al, 2009); nesse sentido, a realização de pesquisa com enfoque qualitativo pode trazer contribuições mais expressivas à academia contábil.

O artigo está estruturado em cinco seções, considerando-se a introdução. Na sequência, tem-se, na seção 2 , o quadro teórico de referência que sustenta a investigação. A seguir, a terceira seção reúne os procedimentos de natureza metodológica empregados no estudo. Na quarta seção é explicitada a análise de dados. Por fim, a quinta seção reúne os argumentos conclusivos da investigação.

\section{Fundamentação Teórica}

Na seção 2 expõem-se a plataforma teórica do estudo. Inicialmente tem-se uma breve exposição sobre gestão ambiental. Na sequência, exploram-se contabilidade ambiental, englobando identificação, mensuração e classificação dos custos ambientais.

\subsection{Gestão Ambiental}

Na visão de Philippi Jr., Roméro e Bruna (2004, p.3) a gestão ambiental configura-se como um processo que se inicia "quando se promovem adaptações ou modificações no ambiente natural, de forma a adequá-los às necessidades individuais ou coletivas [...]". Nesse sentido, o crescimento econômico e social de uma população não pode ter seu planejamento dissociado de aspectos ambientais, devendo ser conduzido de forma consciente, com a devida integração de questões de natureza ambiental e interesses financeiros (ROSSATO; TRINDADE; BRONDANI, 2009; RICHARTZ; FREITAS; PFITSCHER, 2009). Assim, verifica-se que a gestão ambiental é a forma por meio da qual as organizações tentam controlar os impactos ambientais decorrentes de suas atividades. Ressalta-se que o sentido de controle nessa assertiva não está restrito à minimização dos impactos ambientais, mas ao acompanhamento das estratégias e práticas organizacionais alinhadas às questões socioambientais.

O aumento significativo de regulamentação ambiental é um fator que vem contribuindo para o aumento de interesse pelo assunto. Em linhas gerais, tal regulamentação tem determinado penalidades e multas pelo seu descumprimento e incentivos para o seu cumprimento. Todavia, apesar da imposição legal, bem como das pressões sociais que clamam por responsabilidade socioambiental, os custos para o cumprimento de tais regulamentações podem ser bastante significativos, demandando assim, uma análise minuciosa dos custos envolvidos nesse processo proporcionando à empresa, escolhas menos onerosas para tal cumprimento. No entanto, muitas vezes as decisões ambientais são tomadas de forma reativa, 
somente para atender as regulamentações ambientais, e não de forma pró-ativa buscando informações sobre os custos e os benefícios ambientais.

A idéia de sustentabilidade associa-se à exploração dos recursos disponíveis sem prejudicar e desequilibrar o meio ambiente e a sociedade. Para Hansen e Mowen (2003, p. 565) "o desenvolvimento sustentável é definido como o desenvolvimento que satisfaz às necessidades do presente sem comprometer a habilidade de gerações futuras em atender a suas próprias necessidades". Paiva (2003, p. 9) expõe que "parte da responsabilidade por essa conscientização deve-se aos consumidores, que começaram a exigir mais, buscando selecionar produtos que apresentem características específicas, como uma produção 'limpa' do ponto de vista ambiental". Com isso os produtos que não causam danos ao meio ambiente, ou ainda àqueles em que há menção de toda uma preocupação ambiental começaram a ganhar força no mercado, despertando assim, maior preocupação do empresariado com o controle ambiental do processo produtivo, especialmente qunato à emissão de resíduos.

Nesse contexto, Hansen e Mowen (2003) discutem o conceito da ecoeficiência, alertando a necessidade das organizações reduzirem, simultaneamente, os impactos ambientais negativos, o consumo de recursos e os custos relativos a esse processo. Assim, segundo os autores, as empresas estariam atacando as causas e não a problemática apontada pelo debate socioambiental que integra a agenda de inúmeras reuniões empresariais, governamentais, entre outras. Desse modo, visualiza-se que a ecoeficiência tende a crescer paralelamente à obtenção de um melhor desempenho ambiental por parte da instituição que adere à política ecoeficiente. Complementarmente, Vellani e Ribeiro (2009, p. 27) salientam que "a ecoeficiência significa integrar o desempenho econômico e ecológico", expressando assim, a competência da empresa em sua operação sem contaminar o meio ambiente. Logo, o princípio da ecoeficiência está diretamente relacionado ao desenvolvimento sustentável.

\subsection{Contabilidade Ambiental}

Devido a estas mudanças no mercado e na globalização, a contabilidade também precisou passar por adaptações, sendo exigido um enfoque mais analítico, para que pudesse auxiliar nas tomadas de decisões. Segundo Paiva (2003, p. 10) a contabilidade sempre "[...] teve como função primordial o acompanhamento das atividades econômicas, no papel de mensurar e relatar a situação patrimonial das empresas aos principais usuários das informações contábeis, administrativas, sociais e ambientais, acompanhando sua evolução no decorrer do tempo". [Grifo do autor]

Para o atendimento das necessidades dos usuários das informações de 
cunho social e ambiental, e também as exigências legais e normativas, um novo ramo da contabilidade surgiu, a Contabilidade Ambiental, dando ênfase à contabilização dos eventos ambientais e sociais das empresas, a partir de três enfoques: gerencial, financeiro e ambiental. Nessa mesma linha de raciocínio, Rossato, Trindade e Brondani (2009) salientam que os questionamentos acerca do desempenho ecológico das empresas na sociedade trouxeram consigo uma nova perspectiva de visualização da contabilidade; a contabilidade ambiental. De acordo com os autores, o surgimento desse novo ramo da ciência contábil deu-se em 1998, fruto do grupo de trabalho intergovernamental das Nações Unidas de especialistas em padrões internacionais de contabilidade e relatórios.

Segundo Paiva (2003, p. 17) "a contabilidade ambiental serve para registrar e gerar relatórios, com a finalidade de: auxiliar na elaboração do planejamento estratégico; servir de parâmetro no gerenciamento das atividades-alvo; e fornecer informações externas no sentido de prestação de contas dessas atividades". Portanto a contabilidade ambiental tem a finalidade de identificar e registrar os eventos ambientais, subsidiando informações aos usuários e auxiliando na gestão e na tomada de decisões.

Uma alternativa para incrementar o potencial informativo da Contabilidade, a respeito dos eventos ambientais, pode ser obtida por meio de demonstrações complementares, obtidas a partir dos registros extraídos da contabilidade (PAIVA, 2003). Ressalta-se que, ao dispor desse tipo de informações ambientais, a empresa pode utilizá-las para elaboração de indicadores para subsidiar a projeção de cenários futuros. Um dos precursores de tais demonstrativos foi o denominado Balanço Social, que teve início na França na década de 70, passando a ser aderido também por outros países e na década de 80 começou a ser utilizado no Brasil. Para Tinoco e Kraemer (2004, p.87) o "Balanço Social é um instrumento de gestão e de informação que visa evidenciar, de forma mais transparente possível, informações contábeis, econômicas, ambientais e sociais, do desempenho das entidades, aos mais diferentes usuários".

No Brasil, os registros contábeis de natureza ambiental são realizados em consonância com os Princípios Fundamentais de Contabilidade e regidos pela Resolução 750/1993 do Conselho Federal de Contabilidade (CFC). Ainda assim, existem outras normas que foram criadas para estabelecer critérios de tratamento específicos para os eventos ambientais e sociais. Aprovada em 1996, a Norma de Procedimento de Auditoria - NPA11- Balanço e Ecologia, estabelecida pelo Instituto Brasileiro de Contadores (IBRACON), apresenta um rol de implicações decorrentes da ligação entre o meio ambiente e a contabilidade, e que devem ser observadas pelos contadores. Também neste âmbito, o Conselho Federal de Contabilidade elaborou a Norma Brasileira de Contabilidade Técnica NBC T 15, que estabelece procedimentos para evidenciação de informações de natureza 
social e ambiental, com objetivo de demonstrar à sociedade a responsabilidade social das entidades. Estas informações são apresentadas no Balanço Social e na Demonstração do Valor Adicionado (DVA).

\subsubsection{Gastos e Custos Ambientais}

De acordo com Martins (2008), gasto consiste no sacrifício financeiro que a entidade arca para obtenção de um produto ou serviço qualquer. Segundo a contabilidade, serão em última instância classificados como custos ou despesas, a depender de sua importância na elaboração do produto ou serviço. Mas são conceitos distintos, o gasto implica desembolso, pois este representa o pagamento resultante da aquisição de um bem ou serviço, independentemente da data de consumo do produto. O custo, por sua vez, representa o gasto relativo a bens ou serviços utilizados na produção de outros bens ou serviços, estando associado à produção da entidade.

Os custos são elementos essenciais na gestão estratégica das empresas, portanto devem receber especial atenção, com objetivo de contribuir para que a empresa alcance melhores resultados e também de preservar a continuidade do negócio. Em virtude do aumento expressivo do controle ambiental por parte das empresas e do alto investimento que se faz necessário para tal, a gestão dos custos ambientais torna-se uma área estratégica necessitando de um tratamento específico (ROSSATO; TRINDADE; BRONDANI, 2009; MACIEL et al., 2009; VELLANI; RIBEIRO, 2009).

Segundo Hansen e Mowen (2003, p. 566) a redução dos custos ambientais pode criar vantagens competitivas para as empresas, "os custos ambientais podem ser uma porcentagem significativa do total dos custos operacionais e, é interessante mencionar, que muitos desses custos podem ser reduzidos, ou eliminados, por meio de uma gestão eficaz". Como por exemplo, a reavaliação do processo produtivo de um determinado produto, identificando uma possível redução de matéria prima consumida, reduzindo assim custos atuais e futuros.

Conforme Ribeiro apud Ben, Nascimento e Kliemann Neto (2005, p.5035) "os custos ambientais compreendem todos os gastos relacionados direta ou indiretamente com a proteção do meio ambiente [...]". A empresa que consegue identificar e controlar seus gastos ambientais pode obter significativo diferencial competitivo, direcionando de forma mais clara suas políticas de investimentos de curto, médio e longo prazo, modificando sua imagem e agregando valor à sua marca (PAIVA, 2003). Complementarmente, ressalta-se que as empresas que investirem em ações preventivas tendem a reduzir seus custos de remediação.

Segundo Tinoco e Kraemer (2004, p.167) "[...] os gastos e os custos/ despesas das empresas em proteção ambiental, incluindo redução de poluição e 
de resíduos, monitorização da avaliação ambiental, impostos e seguros, têm aumentado rapidamente com a crescente e mais exigente regulamentação ambiental, decorrente da vigília crescente da sociedade”. Em adição, Rossato, Trindade e Brondani (2009) alertam que em virtude da evolução da legislação ambiental que está cada vez mais rigorosa, as empresas passaram a atentar mais aos eventos ambientais, os quais correspondem à interação da empresa com o meio ambiente por meio de seu processo operacional. Contudo, ressalta-se que muitas vezes estes gastos ambientais estão ocultos no processo produtivo da empresa, dificultando assim, sua identificação e mensuração.

\subsubsection{Identificação e Mensuração dos Custos Ambientais}

Diante das exigências do mercado, a identificação dos custos ambientais é essencial para competitividade, pois as empresas estão sendo pressionadas a investirem em questões de natureza ambiental (GUESSER; BEUREN, 1998). Os recursos ambientais incrementam a eficiência da produtividade das operações da empresa e integram os custos de produção. Em alguns casos, a identificação e consequente classificação de tais custos são confusas, dificultando seu registro contábil. Apesar da relevância, muitos custos ambientais têm sua incorporação aos custos dos produtos desprezada, sendo tratados como custos externos. Após a identificação dos custos ambientais, faz-se necessário definir suas formas de mensuração. Conforme Ribeiro (1998, p.1) "a mensuração dos custos ambientais tem esbarrado nas limitações dos instrumentos da Contabilidade, já que, pela sua natureza, a maioria destes custos se enquadra na classificação de custos indiretos e fixos de fabricação [...]".

Em diversos estudos comparativos realizados entre os métodos de custeio, o Activity Based Costing (ABC) foi o mais indicado na análise e mensuração dos custos ambientais das empresas (BEN, 2005). Nesse sentido, na utilização do $\mathrm{ABC}$ para questões ambientais, o objetivo principal consiste na exploração das atividades relevantes para um fim específico, como por exemplo, as atividades associadas ao processo de controle, preservação e recuperação do meio ambiente. Martins (2008) salienta que o ABC é uma poderosa ferramenta a ser utilizada na gestão dos custos, pois não se limita ao custeio dos produtos e oferece subsídios para que se atendam as exigências legais com o mínimo de arbitrariedade no tratamento dos custos indiretos. Portanto, a identificação e mensuração dos custos ambientais são fundamentais para o alcance de resultados mais precisos e tomada de decisão. 
2.2.1.2 Classificação dos Custos Ambientais

A classificação dos custos ambientais, de acordo com Tinoco e Kraemer (2004, p. 169 - 171), dá-se conforme segue:

a) custos externos - Estão fora dos limites da empresa, são custos que podem incorrer como resultado da produção ou existência da empresa, como por exemplo: danos na propriedade de outros, danos econômicos a outros e danos aos recursos naturais;

b) custos internos - São os custos que estão relacionados diretamente com a linha de frente da empresa, como os custos de prevenção e manutenção;

c) custos diretos - Podem ser apropriados para um produto;

d) custos indiretos - São os que não têm vínculo direto com o processo e a gestão ambiental, como por exemplo, treinamento ambiental;

e) custos contingentes ou custos intangíveis - São de maneira geral, potenciais custos internos futuros, que podem impactar nas operações efetivas da empresa.

Podem ser classificados ainda, em:

a) custos potencialmente ocultos - São ligados a todas as atividades necessárias para que a empresa se mantenha em conformidade com as leis e outras políticas ambientais;

b) custos convencionais - Incluem todos os custos associados aos aspectos ambientais tangíveis de tais processos e atividades, como por exemplo, investimentos em equipamentos;

c) custos com contingências - São os gastos que podem ou não ocorrer devido a futuros custos de regulamentações, multas e penalidades;

d) custos de imagem e relacionamento - Envolvem a percepção e o relacionamento que os acionistas, comunidade e governo desenvolvem com a companhia. 


\subsubsection{Evidenciação dos Custos Ambientais}

Os gastos ou custos oriundos de eventos ambientais também produzem efeitos no resultado e na situação patrimonial das empresas, o que implica necessidade de sua evidenciação. De acordo com Paiva (2003, p.45):

Todos os gastos e as provisões efetuados com o meio ambiente devem ser evidenciados, assim como todas as situações relacionadas diretamente com a natureza que possam vir a prejudicar os interesses dos acionistas minoritários ou representem riscos para a continuidade da empresa e da sociedade.

Conforme Rossato, Trindade e Brondani (2009), existem duas linhas de pensamento com relação à evidenciação dos fatos contábeis relacionados ao meio ambiente. Uma defende a implementação de um novo relatório anexo às demonstrações contábeis; a outra a inclusão de informações ambientais nas demonstrações contábeis obrigatórias. Para Ribeiro apud Paiva (2003, p. 48) “a evidenciação dos desembolsos relacionados ao meio ambiente é de relevante importância para atender as necessidades atuais, ou seja, a informação como instrumento de combate à crescente evolução dos níveis de poluição e seus efeitos nocivos". Complementarmente, segundo Ferreira apud Paiva (2003, p. 52) "a inclusão dos aspectos econômicos da questão ambiental nos sistemas de contabilidade das entidades poderia proporcionar maior capacidade de análise [...]”'. Porém, devido à falta de normatização e padronização destes relatórios, poderá haver alguns problemas quanto à credibilidade e veracidade destas informações.

As formas tradicionais de evidenciação de fatos relacionados ao meio ambiente são, de forma complementar ao Balanço Patrimonial e a Demonstração de Resultado, o Relatório da Administração, as notas explicativas e os quadros suplementares. De acordo com Paiva (2003, p.60) "os relatórios contábeis publicados no Brasil, com raras exceções, apresentam-se incompletos no que diz respeito às atividades relacionadas ao meio ambiente. Tanto no relatório da administração como em notas explicativas [...]”. Por isso a utilização de demonstrações complementares, como o Balanço Social e o Eco balanço, pode trazer benefícios à empresa e aos demais usuários, pois englobam informações de cunho social, ambiental e da responsabilidade social da empresa.

Além destes já mencionados, os relatórios de custos ambientais também são essenciais para controle, melhoria do desempenho ambiental e evidenciação dos benefícios trazidos com práticas ambientalmente corretas, como receitas oriundas de projetos de reciclagem e redução dos custos com penalidades e multas pagas em anos anteriores.

\subsubsection{Ativos Ambientais}


De acordo com Paiva (2003) os ativos ambientais representam gastos com investimentos relativos à aquisição de bens relacionados total ou parcialmente com o meio ambiente, adicionados ao processo produtivo para eliminar, reduzir e controlar os níveis de emissão de resíduos e ainda materiais em estoque a serem utilizados na recuperação ou reparos de áreas afetadas, trazendo benefícios futuros. Portanto, ativos ambientais são todos os bens e direitos destinados à atividade de gerenciamento ambiental, com potencial de geração de benefícios futuros.

Um exemplo típico de investimentos ambientais pode ser em "tecnologias limpas", com objetivo de minimizar os resíduos decorrentes do processo produtivo, trazendo benefícios futuros para empresa, para sociedade e o meio ambiente. Outro exemplo é a aquisição de insumos que reduzem a poluição quando aplicados no processo de fabricação, considerados como estoques ambientais. De acordo com o IBRACON- NPA11 (1996), "a configuração dos elementos patrimoniais que compreendem os Ativos Ambientais deve, na contabilidade das empresas, ser apresentada sob títulos e subtítulos específicos, nas demonstrações apresentadas".

\subsubsection{Passivos Ambientais}

Segundo Paiva (2003, p. 34):

As obrigações decorrentes da relação entre empresa e meio ambiente surgem de várias formas, dentre elas com remediação devido ao nãocumprimento da legislação ambiental vigente ou ainda de problema de manutenção ou falhas humanas relacionadas às etapas de produção, potenciais causadores de acidentes.

Desta forma, o passivo ambiental pode ser entendido como toda a agressão que se praticou e/ou pratica contra o meio ambiente e consiste no valor dos investimentos necessários para reabilitá-lo, bem como multas e indenizações em potencial (IBRACON, 1996). Ainda de acordo com o IBRACON (1996), todos os empreendimentos novos, potencialmente poluidores, necessitam elaborar um projeto de proteção ambiental e obtenção prévia das licenças de instalação e operação, junto aos órgãos responsáveis.

Os passivos ambientais podem ser classificados como normais (quanto podem ser controlados) e anormais (quando decorrem de acidentes, não estando sob o controle da entidade). Um passivo ambiental deve ser reconhecido quando existe uma obrigação por parte da empresa que incorreu em um custo ambiental não desembolsado, desde que atenda ao critério de reconhecimento como obrigação. O entendimento dos itens componentes do ativo e passivo ambiental se torna essencial nesse estudo para a correta identificação do objeto de estudo, no caso, os custos ambientais. A seguir na seção 3 encontra-se exposto o direcionamento 
metodológico seguido pela pesquisa em evidência.

\section{Metodologia}

Nessa seção são descritos os procedimentos metodológicos empregados para o desenvolvimento da investigação. No que diz respeito à sua classificação, trata-se de uma pesquisa aplicada, de natureza documental (COOPER e SCHINDLER, 2003), com enfoque qualitativo. O universo da pesquisa é composto por quatro empresas do segmento de Adubos e Fertilizantes, instaladas no Brasil e listadas na BM\&FBOVESPA; são elas: [1] Fertilizantes Fosfatados S.A. - FOSFERTIL; [2] Fertilizantes Heringer S.A.; [3] Nutriplant Indústria e Comercio S.A; e [4] Yara Brasil Fertilizantes S.A.

No que diz respeito à coleta de dados, trata-se de uma pesquisa documental, tendo em vista a recorrência às demonstrações contábeis e relatórios de administração publicados pelas companhias estudadas. Em abril de 2009 foram coletados os relatórios de administração e as demonstrações contábeis relativas ao exercício de 2008 publicadas pelas companhias estudadas. O levantamento realizado e, consequentemente, a análise de documentos, restringem-se aos dois veículos de evidenciação supracitados, não fazendo parte do escopo do presente estudo a exploração de outros registros de natureza contábil, in loco, nas empresas.

Com relação à de análise de dados, recorreu-se à técnica de análise de conteúdo, com utilização do software Atlas.ti ${ }^{\circledR}$ versão 5.0. Ao discorrer acerca do campo de aplicação da análise de conteúdo, Bardin (1977, p. 31) expõe que a referida técnica representa um "conjunto de técnicas de análise das comunicações", configurando-se como um recurso útil nas ocasiões em que se pretende lidar com comunicações, especialmente em situações cuja pretensão está centrada na compreensão para além dos seus significados imediatos.

A seguir, na seção 4 expõe-se a análise de dados do presente estudo.

\section{Análise e Discussão dos Resultados}

Essa seção destina-se à análise dos resultados. Inicialmente tem-se um histórico das companhias estudadas e, na sequência, expõem-se os achados obtidos por meio de análise de conteúdo das Demonstrações Contábeis e do Relatório da Administração.

\subsection{Histórico da Empresa}

A Fertilizantes Fosfatados S.A. também é conhecida fomo FOSFERTIL. A entidade iniciou suas atividades em 1958 como fornecedora de matérias-prima 
e de insumos para indústrias de fertilizantes e empresas químicas. Em adição, presta serviços de logística por meio de seu terminal marítimo, atuando em 4 estados brasileiros. Possui projetos de desenvolvimento limpo, responsabilidade social e ambiental e dispõe de cerca de 3 mil empregados, distribuídos entre as oito unidades no país. O grupo de Fertilizantes Heringer S.A. atua desde 1968 investindo no agronegócio, movimentando esse segmento econômico e gerando empregos em vários estados do país. Pioneira no fornecimento de insumos na zona da mata de Minas Gerais (Manhuaçu), a organização vem ampliando suas fronteiras para atuar também em Viana, no Espírito Santo (ES). Entre as 9 unidades fabris, possui cerca de 1300 funcionários distribuídos entre os setores: industrial, administrativo e comercial.

A Nutriplant Indústria e Comercia S.A. é subsidiária da empresa norteamericana Frit Industries e Ferro Corporation. Constituída em 1979 com o propósito de produzir e comercializar fertilizantes agrícolas específicos, a Nutriplant fornece fertilizantes para nutrição vegetal, micronutrientes, atuando também na linha de produtos industriais, como, por exemplo, na área de pigmentos, papéis, aditivos para tintas, cerâmicas entre outros, atendendo a todas as regiões do território nacional. Por fim, com relação à Yara Brasil Fertilizantes S.A. (Adubos Trevo), observa-se que se trata de uma empresa líder mundial de fornecimento de fertilizantes minerais para plantas, um ingrediente essencial na agricultura moderna, com escritórios em cerca d/e 60 países. No Brasil, o escritório central fica localizado em Porto Alegre, no Rio Grande do Sul (RS). Possui cerca de 1100 colaboradores distribuídos entre as 14 unidades estabelecidas no Brasil.

\subsection{Análise dos Dados}

A análise do conteúdo informacional dos relatórios pesquisados indica que as informações ambientais fornecidas pelas empresas estão concentradas nas Notas Explicativas e no Relatório da Administração. Buscou-se verificar, individualmente, se há classificação e evidenciação dos custos de natureza ambiental nas Demonstrações Financeiras e Relatórios de Administração publicados pelas empresas do segmento de adubos e fertilizantes. Desse modo, em resposta às proposições investigativas desse estudo, optou-se pela exposição das informações pesquisadas por cada uma das empresas do segmento explorado.

A FOSFERTIL ressalta a importância dos aspectos relacionados à responsabilidade social e ambiental por meio de vários projetos que realiza. Ainda menciona que realiza frequentes investimentos em "tecnologia limpa" com intuito de utilizar equipamentos menos poluentes na produção de seus produtos. As principais informações ambientais contidas nas Demonstrações e Relatórios desta empresa referem-se a: [1] sustentabilidade; [2] educação ambiental; [3] 
monitoramento de impactos ambientais; [4] créditos de carbono (CERs); [5] projetos sociais; e [6] tecnologia limpa. A FOSFERTIL assume o compromisso de que a sustentabilidade é parte integrante do seu negócio, atuando ativamente com responsabilidade social e ambiental, conforme ilustrado na Figura 1.

\section{Figura 1 - Sustentabilidade - FOSFERTIL}

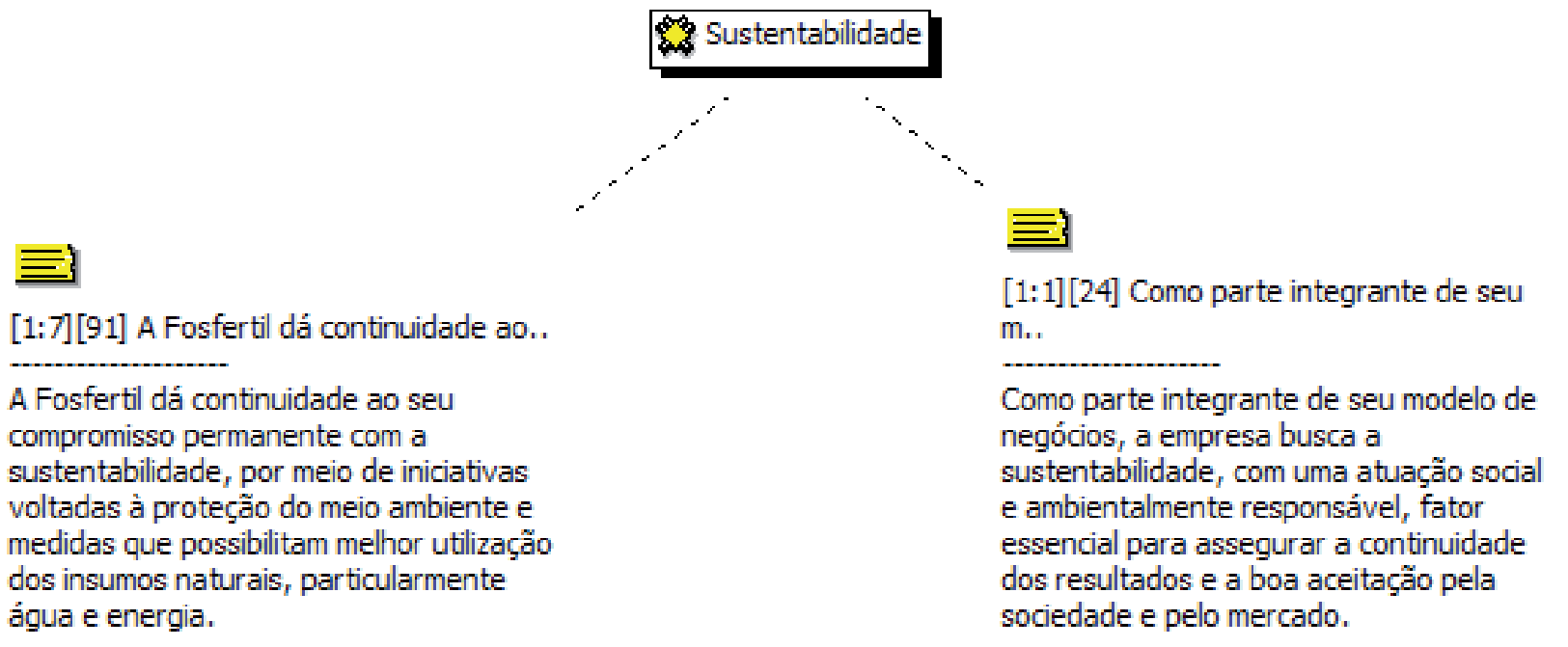

Fonte: Dados da pesquisa.

Complementarmente, na Figura 2 estão descritos os investimentos em modernização tecnológica e melhorias ambientais realizados pela FOSFERTIL no período analisado.

Figura 2 - Tecnologia Limpa- FOSFERTIL

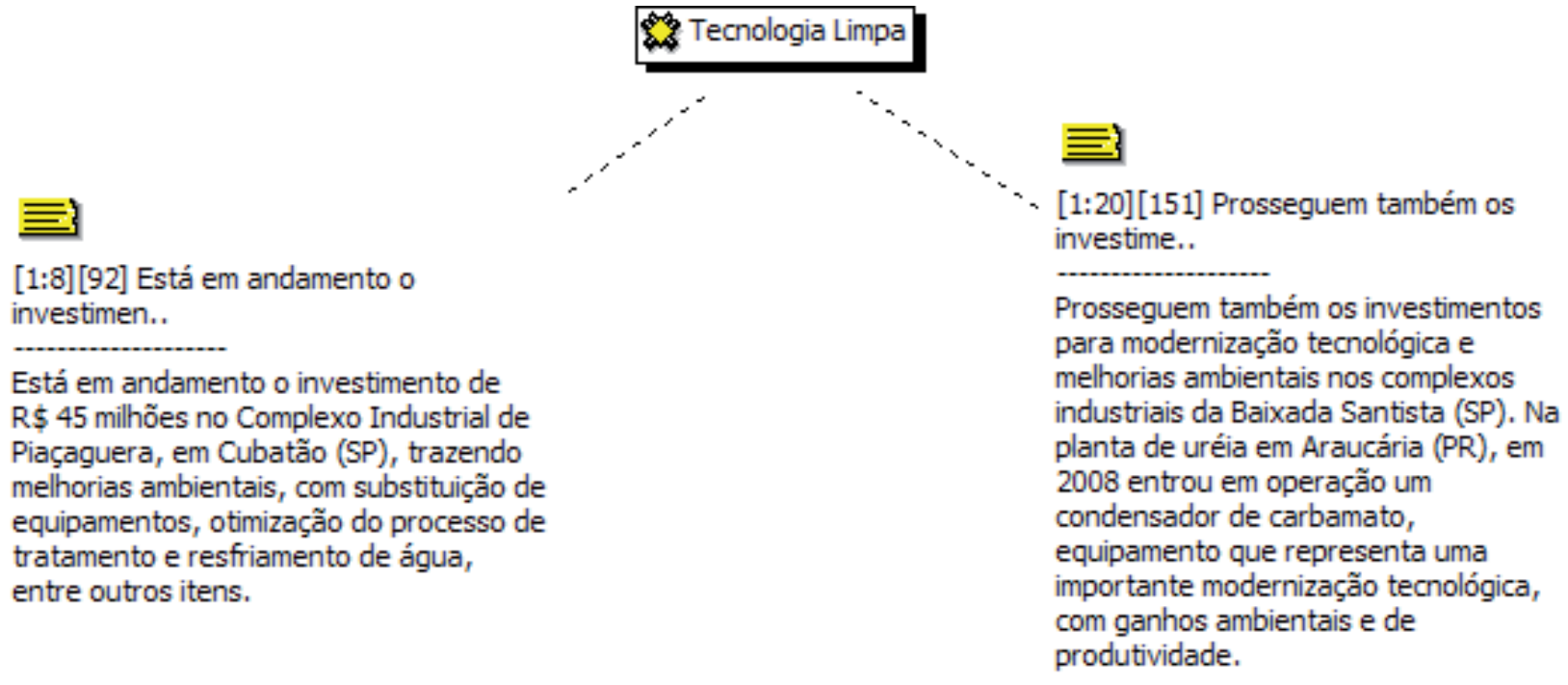

Fonte: Dados da pesquisa.

$\mathrm{Na}$ Figura 3 estão descritos os principais projetos de conscientização ecológica junto à comunidade dos municípios onde a FOSFERTIL atua, auxiliando no processo de educação ambiental capacitando os educadores das escolas 
públicas.

Figura 3 - Educação Ambiental - FOSFERTIL

\section{$\equiv$}

[1:12][98] A Fosfertil ajuda a comunidade..

A Fosfertil ajuda a comunidade dos municípios em que atua a adquirir crescente consciência ecológica. Programas desenvolvidos especialmente com professores e alunos das escolas de ensino fundamental incluem informações sobre preservação de matas ciliares, proteção de mananciais, coleta de lixo e outros aspectos em que a população tem um importante papel a desempenhar.

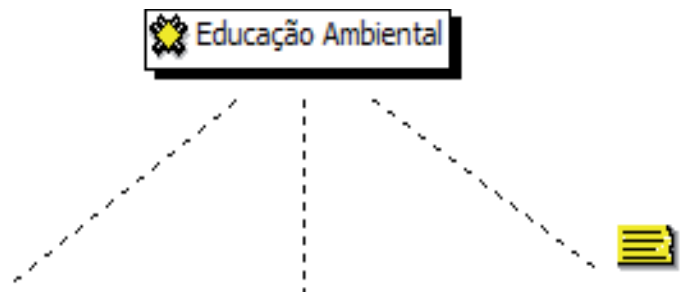

[1:13] [99] Dentro desse mesmo foco, a Fos..

Dentro desse mesmo foco, a Fosfertil patrocinou o projeto Água, Cidadania e Cultura, que levou a Uberaba, Patos de Minas, Patrocínio, Araxá (MG) e Catalão (GO) 35 oficinas de capacitação de educadores, das quais participaram 270 professores, além de distribuir mais de 6.200 kits de material pedagógico para 2.800 escolas públicas dessas regiões.
[1:14][100] Também foi desenvolvido em Ube..

Também foi desenvolvido em Uberaba,

Patrocínio e Cubatão o projeto de educação ambiental Planeta Água, que recebeu diariamente 200 crianças em tendas especialmente montadas em locais estratégicos. Os projetos contaram com apoio do Ministério da Cultura.

Fonte: Dados da pesquisa.

A empresa possui também projetos sociais, como por exemplo, o Projeto Fertilizar que vem beneficiando muitos estudantes. A Figura 4 reúne informações sobre esses projetos.

\section{三. \\ [1:19][119] Como parte das ações desse} pro..

Como parte das ações desse programa, em 2008 as 150 famlias que residiam no Jardim São Marcos (antigo núcleo habitacional que existia na zona industrial de Cubatão-SP) receberam apoio da Fosfertil em seu processo de mudança para um novo conjunto residencial na cidade, chamado Jardim Real, onde participam de um projeto social que está resgatando a cidadania e abrindo novas perspectivas de vida para essa comunidade.

\section{Figura 4 - Projetos Sociais - FOSFERTIL}

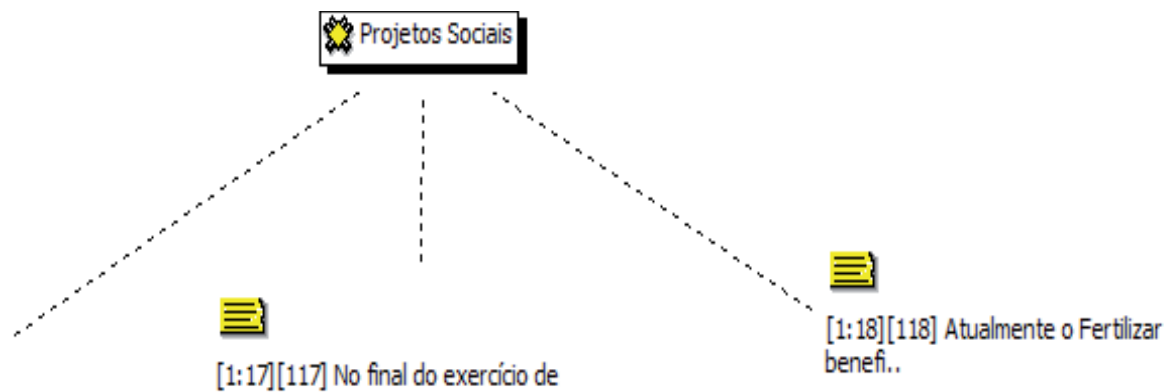
$2008, .$.

Atualmente o Fertilizar beneficia mais de

No final do exercício de 2008 , a Fosfertil destinou R\$ 1,96 milhão para os Fundos Municipais da Infância e Adolescência (FIA) de Araucária (PR), Catalão (GO), Araxá, Patos de Minas, Patrocínio, Tapira, Uberaba (MG), Cubatão, Santos e São Paulo (SP). Nessas cidades, os Conselhos Municipais destinam parcela dos valores doados para projetos apoiados pelo Programa Fertilizar, criado pela Fosfertil com o objetivo de impulsionar a educação para crianças e adolescentes. 
Fonte: Dados da pesquisa.

Com objetivo de prevenir os impactos ambientais causados pela sua atividade, a FOSFERTIL acompanha e monitora o meio ambiente por meio de estudos (Figura 5).

\section{Figura 5 - Monitoramento de Impactos Ambientais - FOSFERTIL}

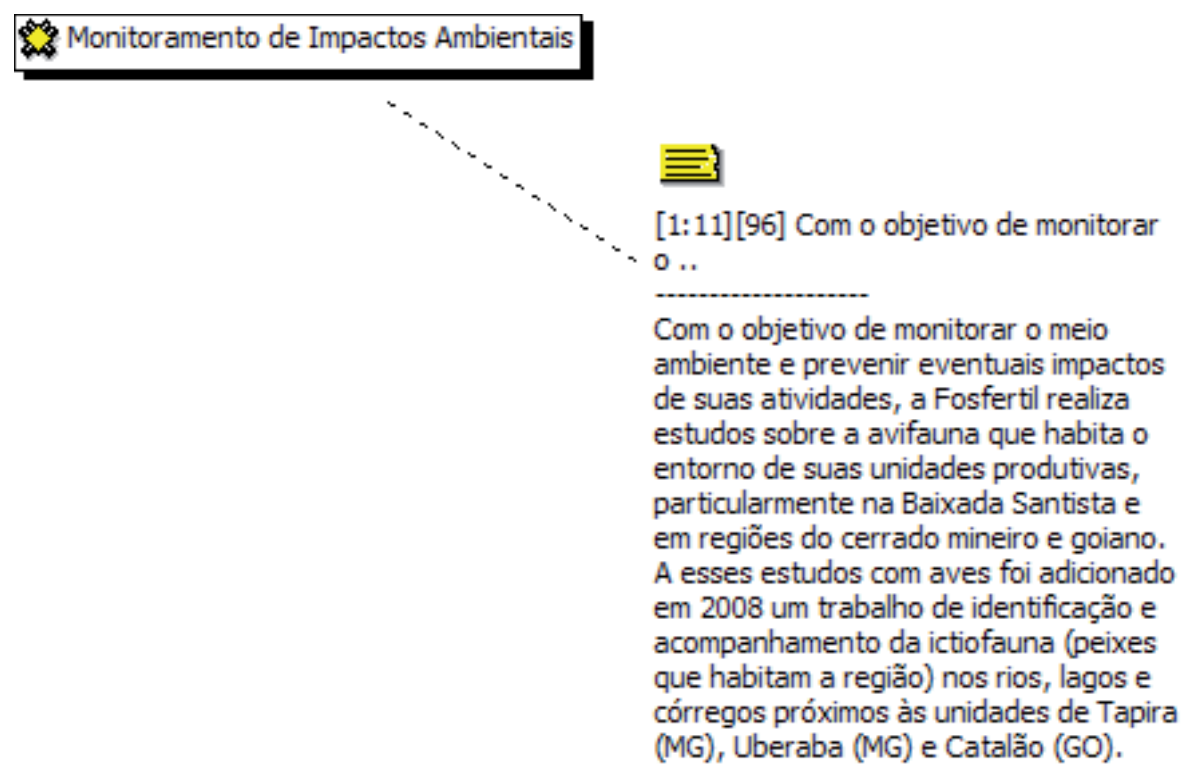

Fonte: Dados da pesquisa.

Conforme a Figura 6, a FOSFERTIL ainda comercializa créditos de carbono (CREs) e aplica a diferença entre o custo anual e os CREs vendidos em melhorias ambientais.

\section{Figura 6 - Créditos de Carbono - FOSFERTIL}

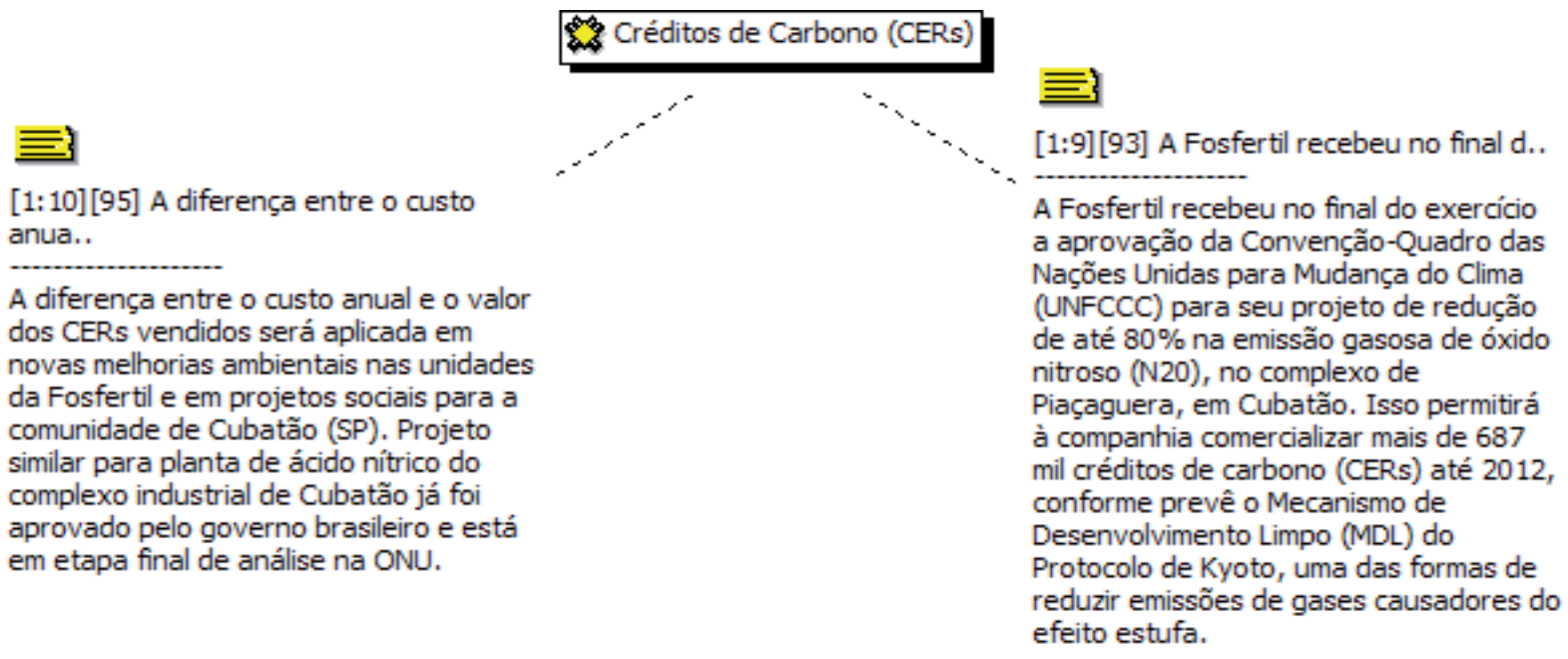

Fonte: Dados da pesquisa.

Apesar das informações ambientais e sociais retiradas das Notas Explicativas e Relatório da Administração da companhia FOSFERTIL, não foram 
encontradas classificação e evidenciação dos custos ambientais nos documentos citados, assim como nas Demonstrações Financeiras.

De forma similar, nos documentos coletados da empresa HERINGER também não foi encontrada evidenciação dos custos ambientais. A empresa possui um sistema de gestão ambiental, mas meramente por preocupação com o atendimento da legislação e normas ambientais, e, possivelmente, não por responsabilidade ambiental e social. Na Figura 7 pode-se compreender melhor o que foi supracitado.

Figura 7 - Sistema de Gestão Ambiental (SGA) - HERINGER

\section{$\equiv$}

[2: 10][1844] Além dos investimentos já real..

Além dos investimentos já realizados nas unidades de produção da Heringer, para a adequação à legislação ambiental, tem sido realizados diversos investimentos adicionais nas unidades de produçãa, como medida preventiva e antecipatória.

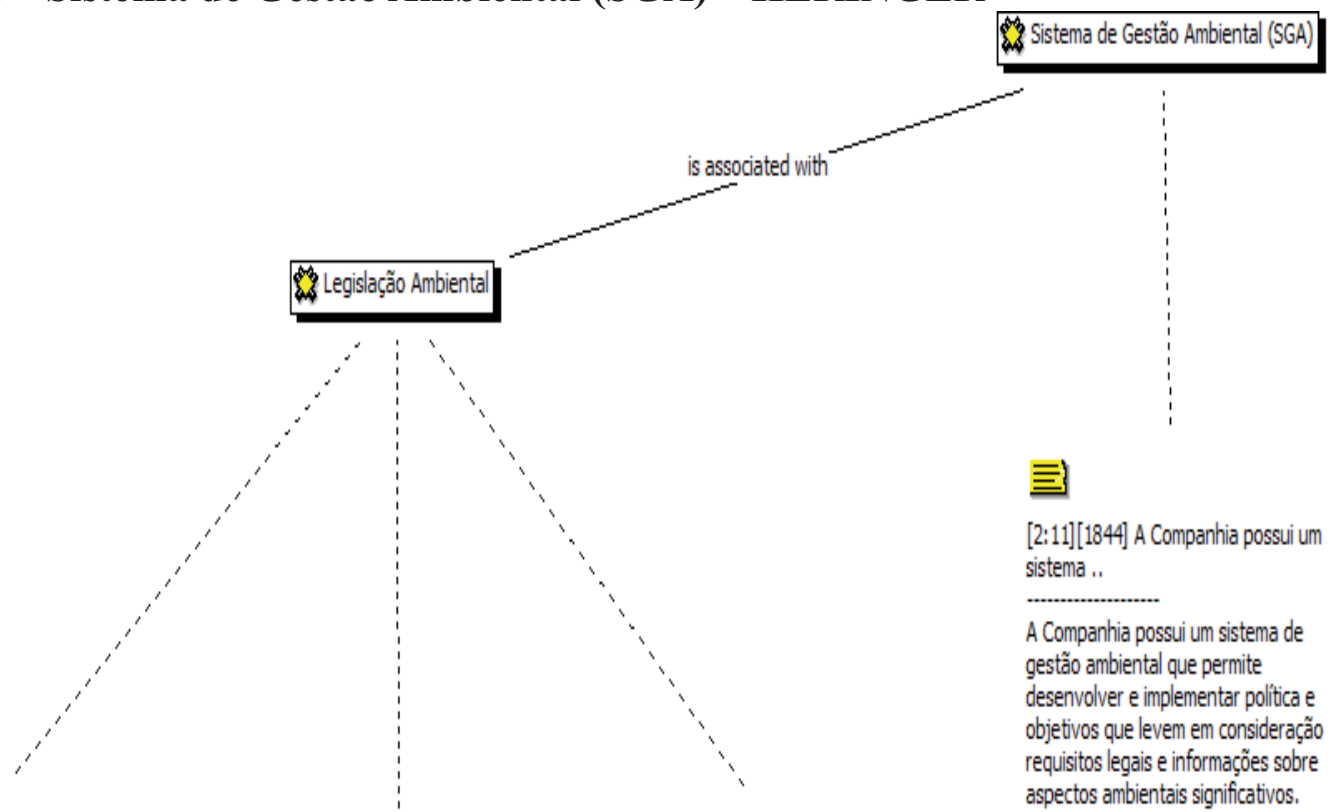

$\equiv$

[2:8][1842] A Companhia está em consonânci..

A Companhia está em consonância com a legislação e normas ambientais vigentes, sendo consideradas e observadas as questôes ambientais nas fases de projeto, construção e operação das unidades industriais misturadoras.

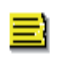

[2:9][1843] Todas as unidades de produção ..

Todas as unidades de produção precisam de autorização dos órgãos reguladores para funcionar e estão sujeitas à supervisão contínua. requisitos legais e informaçoes sobre

Fonte: Dados da pesquisa.

Com relação à empresa NUTRIPLANT, não foram encontradas informações de cunho ambiental e social, somente acerca do desempenho econômico e financeiro da empresa.

A empresa YARA, assim como a FOSFERTIL enfatiza a preocupação com as questões ambientais e sociais, porém também não evidencia os custos de natureza ambiental. Conforme indica a Figura 8, os custos com matéria-prima são bastante significativos em relação aos custos de produção. 
Figura 8 - Custos de Produção - YARA

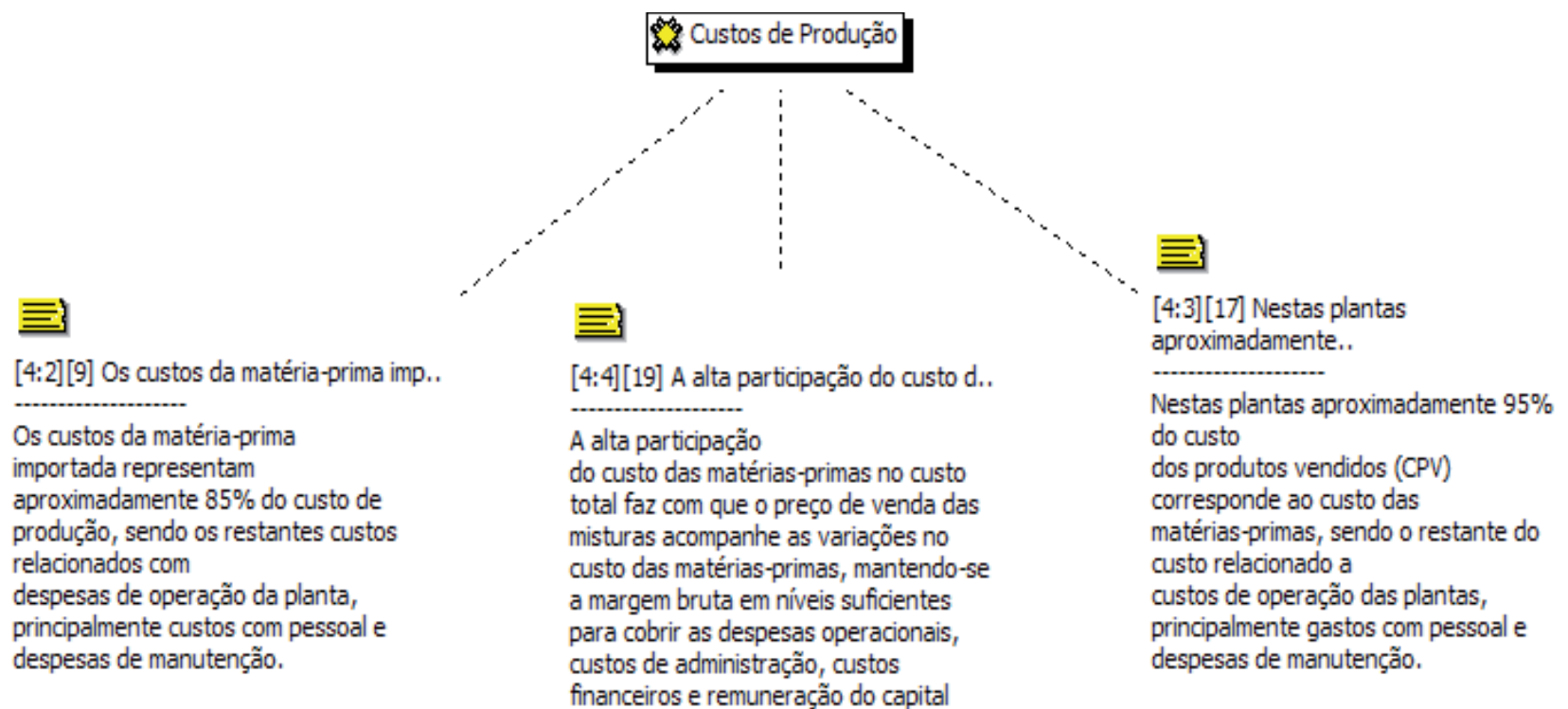

Fonte: Dados da pesquisa.

A YARA diz-se comprometida com a responsabilidade social. A empresa possui vários programas sociais além do programa de voluntariado, conforme a Figura 9.

Figura 9 - Responsabilidade Social - YARA

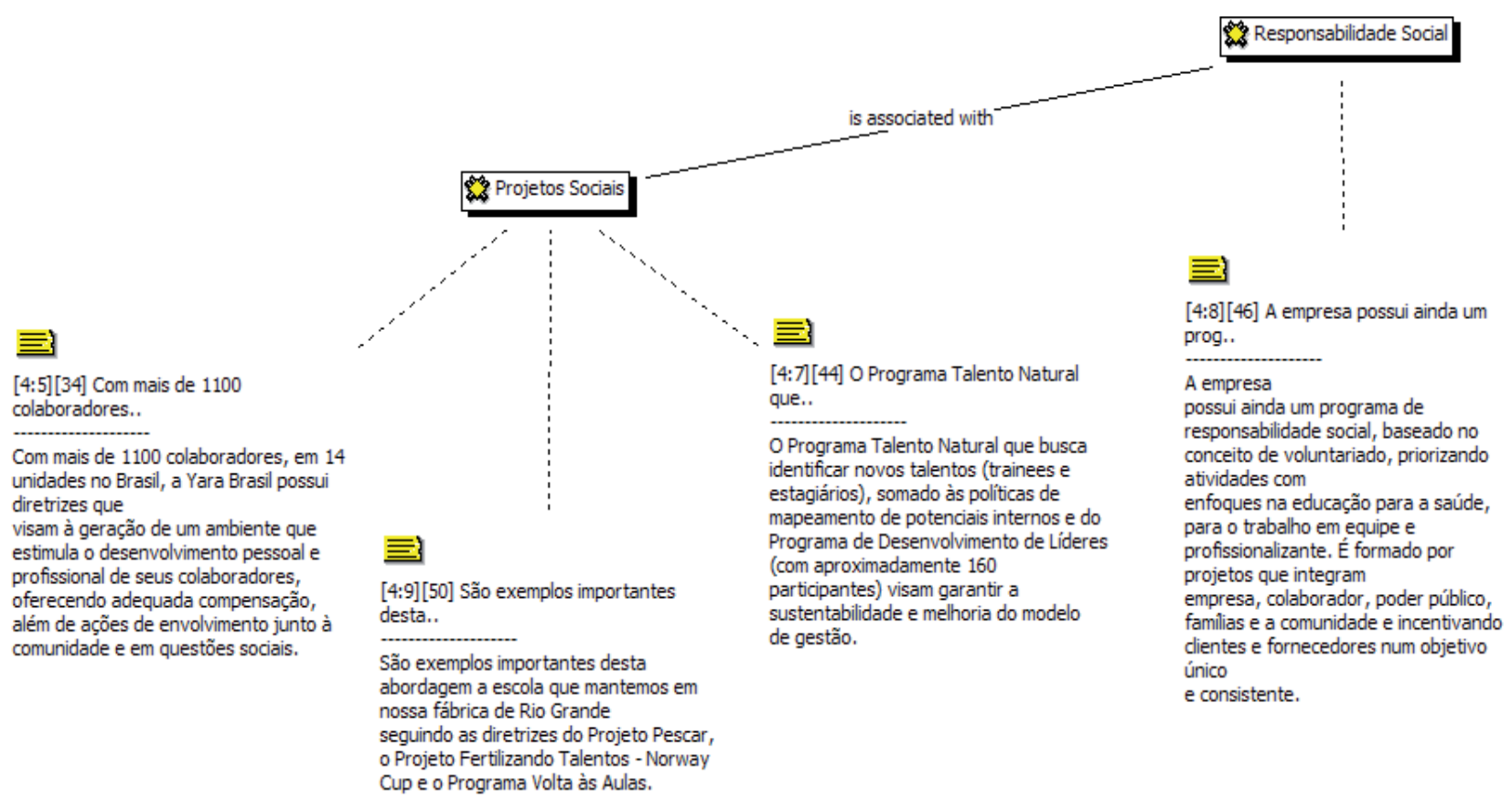

Fonte: Dados da pesquisa.

Possui também um sistema de gestão ambiental integrado a um programa de amplitude global - HESQ (Saúde, Ambiente, Segurança e Qualidade). Além disso, monitora os impactos ambientais. A Figura 10 apresenta esta associação. 
Figura 10 - Sistema de Gestão Ambiental (SGA) - YARA

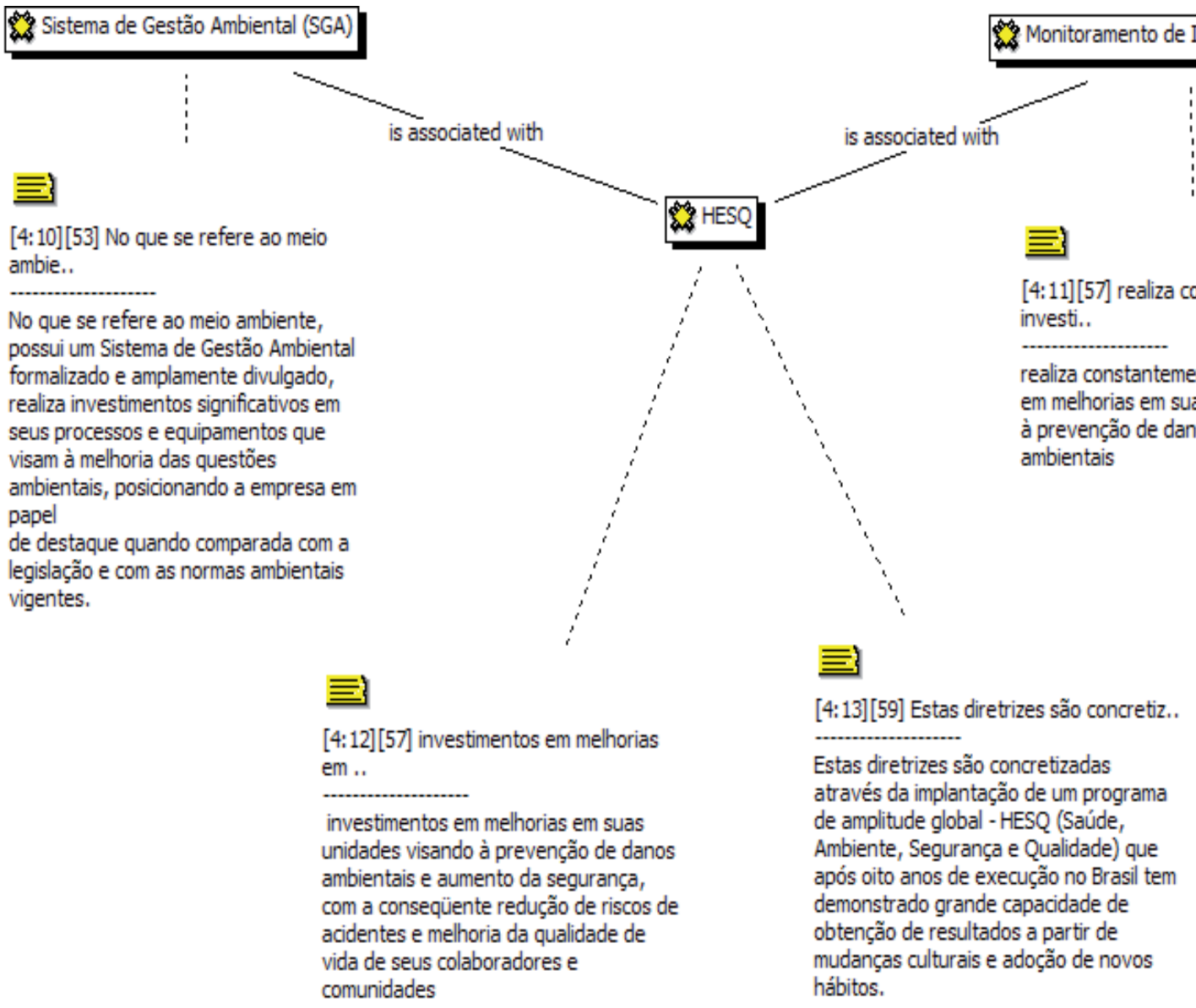

Fonte: Dados da pesquisa.

Expostas as principais informações relativas aos custos de natureza ambiental mencionados nos Relatórios de Administração e nas Demonstrações Contábeis das empresas analisadas, na sequência, a quinta seção destina-se ao fechamento do presente estudo.

\section{Conclusão}

O presente estudo foi desenvolvido com a finalidade de compreender como as empresas do segmento de adubos e fertilizantes têm classificado e evidenciado os custos de natureza ambiental. Por meio da análise dos dados coletados, percebeu-se que, em geral, as empresas enfatizam a preocupação com as questões ambientais (sustentabilidade, responsabilidade social, etc.), mas não evidenciam custos dessa natureza. Em outras palavras, não foram encontradas informações destacadas nos Relatórios da Administração e nas Demonstrações Contábeis das companhias pesquisas que fizessem menção, em termos quantitativos, do volume de recursos que têm canalizado para finalidades sociais e ambientais.

Verificou-se que a evidenciação de custos de natureza ambiental tem-se 
materializado por meio do fornecimento de informações de cunho qualitativo. As empresas estudadas seguem formatos diferenciados de disclosure. Dentre as quatro companhias pesquisadas, a Nutriplant configura-se como aquela instituição que, no período analisado, menos forneceu informações qualitativas sobre suas ações ligadas às questões pesquisadas. Em contrapartida, as demais organizações, apesar de não evidenciarem aspectos quantitativos, manifestaram maior preocupação em informar suas principais práticas socioambientais.

Complementarmente, no tange à classificação dos custos ambientais, verificou-se que as companhias pesquisadas classificaram os investimentos realizados em tecnologia, aquisição de equipamentos utilizados em produção menos poluente, entre outras aplicações, no Ativo Imobilizado, juntamente com os demais ativos, e não como Ativo Ambiental. Desse modo, considerando que, três das quatro companhias pesquisadas afirmaram ter realizado investimentos com finalidades sociais e ambientais, é possível afirmar que não foi realizada classificação dissociada dos ativos dessa natureza. Logo, os custos ambientais foram classificados diretamente como custo de produção.

Diante do exposto, ressalta-se a importância da exigência por meio de lei da evidenciação destas informações, e também de cobrança por parte da sociedade e investidores de maior transparência nas informações divulgadas.

Os resultados do presente estudo sugerem que se esteja enfrentando um processo de mudança de postura por parte das empresas em relação à conscientização ambiental. Essa postura mais responsável é visualizada como algo positivo e que deve ser valorizado. Contudo, pode-se afirmar que tal mudança ainda se encontra em um estágio embrionário, principalmente com relação à combinação das informações ambientais e dos Relatórios de Administração e Demonstrações Financeiras.

No que diz respeito às limitações do presente estudo, ressalta-se que os resultados apresentados estão delimitados pelas empresas estudadas e período explorado. Desse modo, não é possível efetuar generalizações, inclusive com relação às companhias do setor de adubos e fertilizantes, para períodos não abrangidos por este estudo. Ainda com relação às limitações da pesquisa, é oportuno salientar que os resultados apresentados estão condicionados pela política de apresentação de informações das companhias estudadas, uma vez que se trata de uma evidenciação voluntária. Desse modo, é possível que tais organizações estejam adotando práticas não necessariamente mencionadas em seus Relatórios de Administração e Demonstrações Contábeis.

Por fim, com relação às pesquisas que podem ser futuramente desenvolvidas, sugere-se a realização de um acompanhamento da evolução (ou involução) da evidenciação de informações sócio-ambientais das companhias estudadas, com a finalidade de compreender as respostas que tais organizações optaram por dar 
às demandas dos usuários das informações contábeis.

\section{Referências}

BARDIN, L. Análise de Conteúdo. Lisboa: Edições 70. 1977.

BEN, F. Evidenciação de Informações Ambientais pelas Empresas Gaúchas. Revista Universo Contábil. Blumenau, v. 1, n. 3, p. 63-80, Set./Dez. 2005.

BEN, F.; NASCIMENTO, L. F. M.; KLIEMANN NETO, F. J. Análise de custos ambientais em empresa de móveis tubulares. In: XXV Encontro Nacional de Engenharia de Produção - ENEGEP. Porto Alegre/RS. Anais... Porto Alegre: ENEGEP, 2005.

BOLSA DE VALORES, MERCADORIAS E FUTUROS - BM\&FBOVESPA S.A. Demonstrações Financeiras de Empresas Listadas. 2009. Disponível em http://www.bmfbovespa.com.br Acesso em: 20 abr.2009.

CFC - CONSELHO FEDERAL DE CONTABILIDADE. Resolução nº . 750, de 29 de dezembro de 1993. Dispõe sobre os Princípios Fundamentais de Contabilidade. Disponível em: <http://www.portaldecontabilidade.com.br/nbc/res750. htm>. Acesso em: 11 jul. 2009.

CLARKSON, P. M. et al. Revisiting the Relation Between Environmental Performance and Environmental Disclosure: An Empirical Analysis. Accounting, Organizations and Society. n. 33, p. 303-327. 2008.

COOPER, D. R.; SCHINDLER, P. S. Métodos de Pesquisa em Administração. 7. ed. Porto Alegre: Bookman, 2003.

GUESSER, J. M.; BEUREN, I. M. Identificação e Mensuração dos Custos Ambientais. In: V CONGRESSO BRASILEIRO DE CUSTOS, 5., 1998, Fortaleza. Anais... Ceará: ABC, 1998.

HANSEN, D. R.; MOWEN, M. M. Gestão de Custos: Contabilidade e Controle. São Paulo: Pioneira Thomson, 2003.

IBRACON - INSTITUTO BRASILEIRO DE CONTADORES. Norma de Procedimento de Auditoria NPA 11 - Balanço e Ecologia. Diretoria Nacional, 1996. Disponível em: <http://www.ibracon.com.br/publicacoes/resultado. asp?identificador $=223>$. Acesso em: 11 de julho de 2009 .

LIMA, H. M. O.; et al. Gestão dos Custos Ambientais no Co-Processamento de Resíduos Industriais na Votorantim Cimentos N/NE - Unidade de Sobral-CE. 
In: XV CONGRESSO BRASILEIRO DE CUSTOS, 15., 2008, Porto Seguro. Anais... Bahia: ABC, 2008.

MACEDO, M. Á. S.; et al. Desempenhos Socioambiental, Operacional e ContábilFinanceiro no Setor Elétrico Brasileiro: Aplicando DEA na Análise da Sustentabilidade Multidimensional. In: Encontro Anual da Associação Nacional dos Programas de Pós-Graduação em Administração - EnANPAD, 32., 2008, Rio de Janeiro. Anais... Rio de Janeiro: ANPAD, 2008.

MACIEL, C. V., LAGIOIA, U. C. T., LIBONATI, J. J., RODRIGUES, R. N. Contabilidade Ambiental: Um Estudo Exploratório sobre o Conhecimento das Profissionais de Contabilidade. Revista Contemporânea de Contabilidade. v.1, n.11, p. 137-158, jan./jun., 2009.

MARTINS, E. Contabilidade de Custos. 9. ed. São Paulo: Atlas, 2008.

PAIVA, P. R. Contabilidade Ambiental: Evidenciação dos Gastos Ambientais com Transparência e Focada na Prevenção. São Paulo: Atlas, 2003.

PHILIPPI JR, A.; ROMÉRO, M. de A.; BRUNA, G. C. Curso de Gestão Ambiental. Barueri, SP: Manole, 2004. (Coleção Ambiental: 1).

RIBEIRO, M. S. O Custeio por Atividades Aplicado ao Tratamento Contábil dos Gastos de Natureza Ambiental. Caderno de Estudos FIPECAFI. v.10, n. 19, p. 82-91, 1998.

RICHARTZ, F., FREITAS, C. L., PFISTCHER, E. D. Analise de Sustentabilidade Ambiental em uma Industria de Bebidas: Um Enfoque no Processo Produtivo. Revista Contemporânea de Contabilidade. v.1, n.12, p. 35-52, jul./dez., 2009.

ROSSATO, M. V.; TRINDADE, L. L.; BRONDANI, G. Custos Ambientais: Um Enfoque para a sua Identificação, Reconhecimento e Evidenciação. Revista Universo Contábil. Blumenau, v. 5, n. 1, p. 72-87, Jan./Mar. 2009.

ROVER, S.; et al. Explicações para a Divulgação Voluntária Ambiental no Brasil Utilizando Análise de regressão em Painel. In: CONGRESSO IAAER - ANPCONT INTERNATIONAL ACCOUNTING CONGRESS, 3., 2009, São Paulo. Anais ... São Paulo: ANPCONT, 2009.

TINOCO, J. E. P.; KRAEMER, M. E. P. Contabilidade e Gestão Ambiental. São Paulo: Atlas, 2004.

VAZ, A. C.; et al. Análise Comparativa sobre Informações Voluntárias Divulga- 
das: o Social Disclosure das Empresas Latino-Americanas Listadas na Nyse. In: Encontro Anual da Associação Nacional dos Programas de Pós-Graduação em Administração - EnANPAD, 32., 2008, Rio de Janeiro. Anais... Rio de Janeiro: ANPAD, 2008.

VELLANI, C. L; RIBEIRO, M. S. Sistema Contábil para Gestão da Ecoeficiência Empresarial. Revista Contabilidade \& Finanças. v. 20, n. 49, p. 25-43, Jan./Abr. 2009.

VELLANI, C. L; RIBEIRO, M. S. Sustentabilidade e Contabilidade. Revista Contemporânea de Contabilidade. v.1, n.11, p. 187-206, jan./jun., 2009. 
